\title{
A Retrospective Analysis of the Management of Postoperative Discitis: A Single Institutional Experience
}

\author{
R. Santhanam ${ }^{1}$, K. Lakshmi ${ }^{2}$ \\ ${ }^{1}$ Department of Neurosurgery, Sree Balaji Medical College and Hospital, Bharath University, Chennai, India \\ ${ }^{2}$ Department of Microbiology, Sree Balaji Medical College and Hospital, Bharath University, Chennai, India
}

\begin{abstract}
Study Design: Retrospective study.
Purpose: The aim of the study was to study the impact and outcome of conservative management and surgical intervention in cases of postoperative discitis.

Overview of Literature: Postoperative discitis is a rare but often misdiagnosed cause of failed back syndrome. There is paucity of literature regarding management guidelines of postoperative discitis.

Methods: The study was carried out over a period of 6 years. Eighteen patients with postoperative discitis were included in the study.

Results: Conservative management with antibiotics, analgesics and bed rest were started in all the study cases. Posterior transpedicular fixation after re-exploration debridement and curettage of disc space granulation tissue was conducted in five patients in whom conservative management failed.

Conclusions: Early diagnosis and appropriate management is the key to effective treatment of postoperative discitis. Conservative management leads to excellent results in majority of cases. Surgical intervention with posterior interbody fusion and debridement is helpful when conservative treatment fails.
\end{abstract}

Keywords: Lumbar discectomy; Postoperative discitis; Antibiotic therapy; Posterior transpedicular fixation

\section{Introduction}

Discitis is defined as the inflammation of vertebral end plates due to infective cause. Postoperative discitis (POD) can occur after lumbar discectomy. Nucleus pulposus is primarily affected along with infection of vertebral body and cartilaginous end plate. Infection of the disc space may often produce debilitating neurologic illnesses. Discitis usually presents with severe back pain, muscle spasm and fever. Blood tests may show an increase in erythrocyte sedimentation rate (ESR), leukocyte cell counts, and C-reactive protein (CRP). Radiological findings may show reduction in disc space and end space blurring/resorption. Histological findings show inflammation along with granulation tissue in disc and vertebral body and disc vascularisation. Positive cultures may be seen in $42 \%$ to $73 \%$ cases $[1,2]$.

Early diagnosis and appropriate management of disci-

Received Jan 2, 2015; Revised Jan 19, 2015; Accepted Jan 20, 2015

Corresponding author: R. Santhanam

Department of Microbiology, Sree Balaji Medical College and Hospital,

\#7, Works Road Chromepet Chennai, 600044 Tamil Nadu, India

Tel: +91-94-4534-9440, Fax: +91-44-2241-6676, E-mail: drsanthanam79@yahoo.co.in 
tis can reduce morbidity [3]. Conservative management with bed rest, antibiotics and analgesics are adequate in most cases. Antibiotics should be initiated after culture and sensitivity. Surgical treatment should be considered if conservative management fails. In the present study, we retrospectively analyzed a series of patients with discitis after lumbar disc surgery and determined the outcome of the patients with conservative management vs. surgical intervention.

\section{Materials and Methods}

A retrospective analysis of patients who underwent lumbar laminectomy and discectomy over a period of 6 years from 2009 to 2014 was conducted. In the 6-year period, 152 patients underwent 160 surgical procedures for disc prolapse. Clinico-radiological correlation was ascertained in all patients before surgery. The follow-up period ranged from 6 months to 5 years.

Eighteen patients who presented with features of POD, with severe back pain after lumbar disc surgery were included in the study. They had positive straight leg raising test and restricted movements on examination. Blood tests, X-ray, computed tomography (CT), magnetic resonance imaging (MRI) lumbosacral spine were used to confirm diagnosis in all patients. Three other cases of recurrent disc prolapse without features of discitis were excluded from the study although they needed resurgery. All 18 patients received conservative management with empirical antibiotics, analgesics, physiotherapy and complete bed rest. All the patients were followed up for 3 to 4 weeks. Patients with improved symptoms and lab investigations continued to be managed conservatively. Five patients were selected for surgery that included posterior interbody fusion after debridement. Culture and sensitivity tests showed Staphylococcus aureus growth in one patient and no growth in the remaining.

All patients were followed up regularly for a period of 1 year.

\section{Results}

This study was done in a tertiary care hospital over a period of 6 years. One hundred and fifty-two patients with disc prolapse were included in the study. Majority of patients were between 30 to 60 years (Table 1). Eighty-eight patients had L4-L5 level involvement and 51 patients had lesion at L5-S1 level.

Eighteen patients had symptoms of discitis within 2 weeks. Among the 18 cases diagnosed with discitis, 12 cases were operated in Sree Balaji Medical College and Hospital, and the remaining were operated elsewhere and presented with symptoms of discitis to our hospital outpatient department.

Almost all patients had severe back pain. Radicular pain with muscle spasm was the presenting feature in most cases. Pain was radiating to groin, buttocks and thigh. Local tenderness was present in the affected site. Straight leg raising test was positive in most cases. However, it was not performed in few cases due to severe pain. Fever occurred in $30 \%$ cases; ESR was elevated in $88 \%$ cases; and CRP was increased in $81 \%$ cases. Eighty percent of patients had disc space narrowing and end plate resorption. MRI in $60 \%$ patients showed typical florid inflammation and granulation tissue with low signal intensity in T1 images and high signal intensity in T2-weighted images (Fig. 1).

Table 1. Age wise distribution of cases

\begin{tabular}{lc} 
Age $(y r)$ & No. of patients \\
$<30$ & 22 \\
$30-60$ & 98 \\
$>60$ & 18 \\
\hline
\end{tabular}

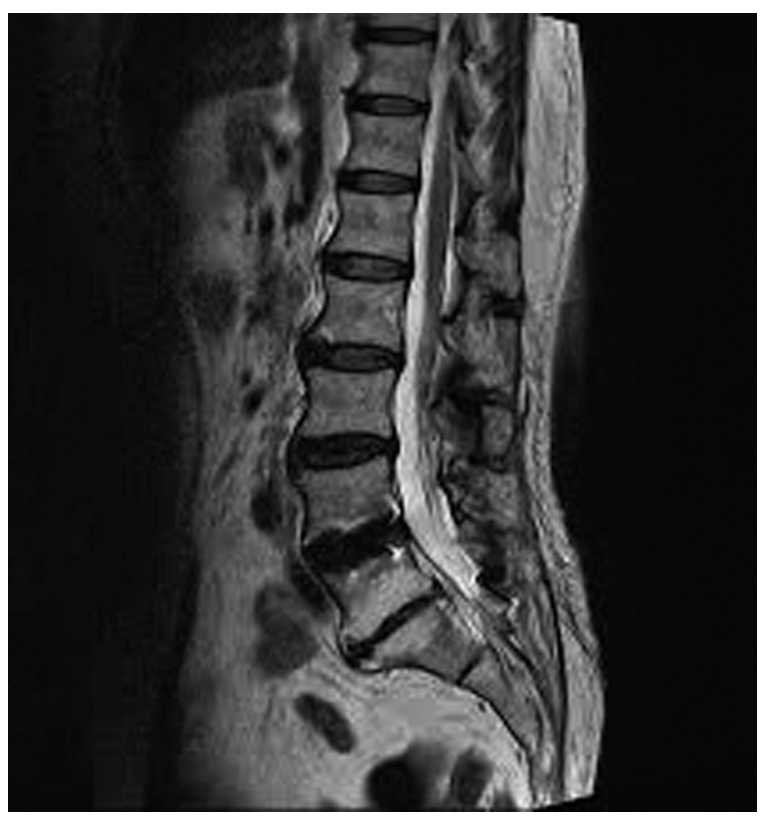

Fig. 1. Magnetic resonance imaging lumbosacral spine T2weighted sagittal image showing postoperative discitis at the L5S1 level. 
MRI showed fluid collection in $10 \%$ cases. Percutaneous biopsy was not performed. Three of the operated cases had open debridement procedure and disc space samples were sent for culture and sensitivity. One sample showed $S$. aureus and two had no growth.

All patients were advised complete bed rest. They were started on analgesics, oral or intravenous antibiotics. Fourteen of 18 patients showed improvement with conservative management on regular follow-up. However, one patient who improved with conservative treatment had relapse and wound discharge 6 months later that required surgery.

The other four cases did not respond to conservative management. Hence, 5 of the 18 cases were finally selected for surgery. Re-exploration debridement and curettage of disc space granulation tissue with posterior transpedicular fixation was conducted in all cases (Fig. 2). They were mobilised within 48 hours after surgery. None of them had any neurological deterioration or wound infection.

\section{Discussion}

Discitis rarely occurs spontaneously but is not uncom-

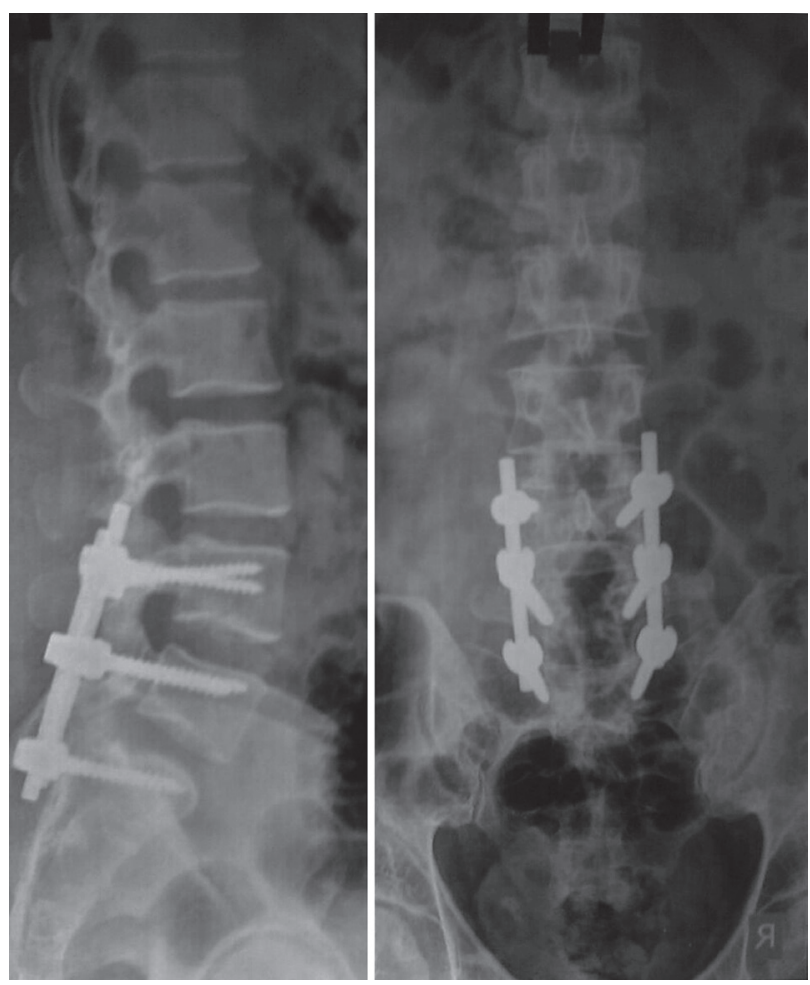

Fig. 2. X-ray lumbosacral spine showing L4, L5, S1 level transpedicular fusion. mon after surgical treatment for disc prolapse. POD can be either septic or aseptic. Many studies showed that it could be due to bacterial causes [4-6].

In our study, 18 patients had POD over a period of 6 years with an average of 3-4 case/year. Ahmad and Ya$\sin [7]$ reported an incidence of 6 case/year.

In our study, most cases of discitis belonged to the 40 to 70 years age group. Occurrence of discitis was high in patients with recurrent disc surgeries as previously reported [7]. The period between the surgery and the onset of symptoms was 14 to 24 days. Clinical presentation in most of the cases in our study was similar to the existing literature $[8,9]$. The characteristic symptoms in our cases were severe increasing back pain, muscle spasm and fever; radicular pain was also a common finding.

Early and accurate diagnosis of discitis that correlates with clinical, laboratory and radiological findings is required. Persistent elevated ESR and CRP together with typical findings in MRI suggests discitis [10,11]. Increased ESR and CRP are suggestive but not confirmatory of the diagnosis. CRP typically declines by around 10 days postoperatively, hence any patient with unexpected rise in CRP beyond 2 weeks postsurgery should be suspected for POD. Some studies indicate that CRP is the most sensitive indicator of POD $[12,13]$. Around $88 \%$ patients in our study had increased ESR, $41 \%$ had increased white blood cell count and $81 \%$ showed increased CRP that corroborated previous studies [13-15].

Clinical MRI is the most superior diagnostic method [16]. MRI reportedly has good sensitivity and specificity $[10,16]$. Florid inflammatory signs with granulation tissue were identified on MRI in most of our cases, as previously reported [7,17].

Silber et al. [18] showed that $S$. aureus is a common organism. Yang et al. [19] showed that after spondylodiscitis, the causative organism was identified more frequently with percutaneous endoscopy (90\%) than CT-guided biopsy (47\%). They also showed that simple aspiration of the disc space may lead to false negative results. Thin bore needle may not yield sufficient infective material for microbiological investigation. Also, there could be mixed infections with anaerobes that may be difficult to diagnose. Proper and timely identification of the causative organism and specific antimicrobial management is very important to prevent possible severe complications of infectious discitis [8].

Pathogen detection by conventional microbiologi- 
cal methods has certain limitations such as low number of microorganisms and non-cultivable or slow growing organisms. However, amplification based DNA analysis molecular methods can overcome most limitations of microbiological methods. Molecular methods have their own limitations [20], such as false positive results due to improper sample collection $[21,22]$ and false negative results due to very few organisms and presence of polymerase inhibitors. DNA analysis by molecular methods is considered a useful adjunct rather than an alternative to culture methods [23]. However, DNA array based typing needs further development and intense research.

Thus, empirical antibiotic management is the only treatment course when identification of the causative pathogen is lacking. In our study, antibiotic treatment was started in all cases and the patients showed fall in ESR and CRP levels with clinical improvement in 1 to 4 weeks. There is no standardised management protocol for discitis. Complete bed rest and antibiotics remain the main stay of management $[18,24]$. Conservative treatment and spinal immobilisations yield good outcomes in most cases [18]. On the other hand, long term antibiotic therapy reportedly has some complications and side effects [25]. The literature indicates that IV infusion of antibiotics should be initiated for 4 to 6 weeks followed by oral therapy for 2 to 3 months $[9,26]$. Failure results were high in intravenous therapy of less than 4 weeks $[9,26]$.

The patients in our study were selected for surgery early if they did not respond to antibiotic treatment. All the patients were advised complete bed rest with analgesics and antibiotics including vancomycin, linezolid, and cefaperazone with sulbactum. Fourteen of 18 patients improved in response to conservative management on regular followup. However, one patient who improved with conservative treatment had relapse and wound discharge 6 months later that required surgical treatment.

Other four cases presented with symptoms even after conservative management. Hence, a total of five patients of 18 cases were finally selected for surgery. Surgery for all the cases of POD was done through the posterior approach. Reexploration debridement and curettage of disc space granulation tissue with inter transpedicular fixation was conducted in all cases. Surgery in POD at the L4/5 and L5/S1 levels through the anterior approach is quite difficult and morbidity is also high. But the disc space can be approached more easily from the posterior side. Instrumentation helps in stabilising the infected spine more ef- fectively and hastens the healing process [27,28]. Another study by Przybylski and Sharan [29] reported that single stage debridement, arthrodesis and internal fixation can be used as surgical management of pyogenic discitis with vertebral osteomyelitis without much complication.

Percutaneous endoscopic biopsy could be useful in identifying the pathogen $[14,26]$. S. aureus was the most common organism in positive cultures in many studies $[24,30]$. Culture and sensitivity was done in four cases in our study. Broad spectrum antibiotics were directly initiated by IV in most of the cases.

The prognosis of discitis varies with different authors. Few studies showed that mild back pain occurred in almost all patients [24]. But in our study, almost all the patients were mobilised within 48 hours after surgery. None of them had any neurological deterioration or wound infection. All patients returned to their normal daily activities within 6 months.

\section{Conclusions}

POD is a rare but serious complication of disc surgeries. Discitis should be suspected in all patients with unexplained persistent back pain beyond 2 weeks of surgery or any other exaggerated symptoms. Careful evaluation is required in such cases. Early diagnosis and appropriate management lead to a good prognosis. Conservative treatment with complete bed rest and proper antibiotic therapy itself is the main stay of management in majority of cases. Surgical treatment including debridement, fixation and fusion is required if conservative management fails. Percutaneous transpedicular fixation can also be considered. The prognosis of discitis is good in most cases without major complications.

\section{Conflict of Interest}

No potential conflict of interest relevant to this article was reported.

\section{References}

1. Onik G. Automated percutaneous biopsy in the diagnosis and treatment of infectious discitis. Neurosurg Clin N Am 1996;7:145-50.

2. Sharma SK, Jones JO, Zeballos PP, Irwin SA, Martin TW. The prevention of discitis during discography. 
Spine J 2009;9:936-43.

3. Luzzati R, Giacomazzi D, Danzi MC, Tacconi L, Concia E, Vento S. Diagnosis, management and outcome of clinically-suspected spinal infection. J Infect 2009;58:259-65.

4. Osti OL, Fraser RD, Vernon-Roberts B. Discitis after discography: the role of prophylactic antibiotics. J Bone Joint Surg Br 1990;72:271-4.

5. Tronnier V, Schneider R, Kunz U, Albert F, Oldenkott P. Postoperative spondylodiscitis: results of a prospective study about the aetiology of spondylodiscitis after operation for lumbar disc herniation. Acta Neurochir (Wien) 1992;117:149-52.

6. Fraser RD, Osti OL, Vernon-Roberts B. Iatrogenic discitis: the role of intravenous antibiotics in prevention and treatment: an experimental study. Spine (Phila Pa 1976) 1989;14:1025-32.

7. Ahmad M, Yasin M. Lumbar discitis: prevalence and management after lumber disc surgery. Prof Med J 2010;17:628-632.

8. Jimenez-Mejias ME, de Dios Colmenero J, SanchezLora FJ, et al. Postoperative spondylodiskitis: etiology, clinical findings, prognosis, and comparison with nonoperative pyogenic spondylodiskitis. Clin Infect Dis 1999;29:339-45.

9. Rohde V, Meyer B, Schaller C, Hassler WE. Spondylodiscitis after lumbar discectomy: incidence and a proposal for prophylaxis. Spine (Phila Pa 1976) 1998; 23:615-20.

10. Frank AM, Trappe AE. The role of magnetic resonance imaging (MRI) in the diagnosis of spondylodiscitis. Neurosurg Rev 1990;13:279-83.

11. Boden SD, Davis DO, Dina TS, Sunner JL, Wiesel SW. Postoperative diskitis: distinguishing early MR imaging findings from normal postoperative disk space changes. Radiology 1992;184:765-71.

12. Meyer B, Schaller K, Rohde V, Hassler W. The Creactive protein for detection of early infections after lumbar microdiscectomy. Acta Neurochir (Wien) 1995;136:145-50.

13. Perronne C, Saba J, Behloul Z, et al. Pyogenic and tuberculous spondylodiskitis (vertebral osteomyelitis) in 80 adult patients. Clin Infect Dis 1994;19:746-50.

14. Fouquet B, Goupille P, Jattiot F, et al. Discitis after lumbar disc surgery: features of "aseptic" and "septic" forms. Spine (Phila Pa 1976) 1992;17:356-8.

15. Kapp JP, Sybers WA. Erythrocyte sedimentation rate following uncomplicated lumbar disc operations. Surg Neurol 1979;12:329-30.

16. Van Goethem JW, Parizel PM, van den Hauwe L, Van de Kelft E, Verlooy J, De Schepper AM. The value of MRI in the diagnosis of postoperative spondylodiscitis. Neuroradiology 2000;42:580-5.

17. Wirtz DC, Genius I, Wildberger JE, Adam G, Zilkens KW, Niethard FU. Diagnostic and therapeutic management of lumbar and thoracic spondylodiscitis: an evaluation of 59 cases. Arch Orthop Trauma Surg 2000;120:245-51.

18. Silber JS, Anderson DG, Vaccaro AR, Anderson PA, McCormick P. Management of postprocedural discitis. Spine J 2002;2:279-87.

19. Yang SC, Fu TS, Chen LH, Chen WJ, Tu YK. Identifying pathogens of spondylodiscitis: percutaneous endoscopy or CT-guided biopsy. Clin Orthop Relat Res 2008;466:3086-92.

20. Burkardt HJ. Standardization and quality control of PCR analyses. Clin Chem Lab Med 2000;38:87-91.

21. Corless CE, Guiver M, Borrow R, Edwards-Jones V, Kaczmarski EB, Fox AJ. Contamination and sensitivity issues with a real-time universal $16 \mathrm{~S}$ rRNA PCR. J Clin Microbiol 2000;38:1747-52.

22. Carroll NM, Adamson P, Okhravi N. Elimination of bacterial DNA from Taq DNA polymerases by restriction endonuclease digestion. J Clin Microbiol 1999;37:3402-4.

23. Lecouvet F, Irenge L, Vandercam B, Nzeusseu A, Hamels S, Gala JL. The etiologic diagnosis of infectious discitis is improved by amplification-based DNA analysis. Arthritis Rheum 2004;50:2985-94.

24. Dall BE, Rowe DE, Odette WG, Batts DH. Postoperative discitis: diagnosis and management. Clin Orthop Relat Res 1987;(224):138-46.

25. Mann S, Schütze M, Sola S, Piek J. Nonspecific pyogenic spondylodiscitis: clinical manifestations, surgical treatment, and outcome in 24 patients. Neurosurgical Focus 2004;17:E3.

26. Levi AD, Dickman CA, Sonntag VK. Management of postoperative infections after spinal instrumentation. J Neurosurg 1997;86:975-80.

27. Rayes M, Colen CB, Bahgat DA, et al. Safety of instrumentation in patients with spinal infection. J Neurosurg Spine 2010;12:647-59.

28. Lee MC, Wang MY, Fessler RG, Liauw J, Kim DH. Instrumentation in patients with spinal infection. 
Neurosurg Focus 2004;17:E7.

29. Przybylski GJ, Sharan AD. Single-stage autogenous bone grafting and internal fixation in the surgical management of pyogenic discitis and vertebral osteo- myelitis. J Neurosurg 2001;94:1-7.

30. Rawlings CE 3rd, Wilkins RH, Gallis HA, Goldner JL, Francis R. Postoperative intervertebral disc space infection. Neurosurgery 1983;13:371-6. 